\title{
Treball
}

Bibliografia relativa al tema (Trabajo), 32:127.

Weber, Max.

CabreRA VARELA, Julio. Repertorio bibliográfico castellano de Max Weber, 24:175.

\section{NOTES D'INVESTIGACIÓ}

Ávila, Raúl A. El Cordobazo: la violencia y sus protagonistas, 1:127.

BAYES, Ramón. Control de natalidad y mongolismo, 2:117.

Cano Tembleque, José. Notas de lectura del ¿Qué hacer? de Lenin, 1:136. EsTRUCH, Joan; GUELI, Antonio M. La elección de carrera y sus motivaciones, $4: 183$.

MIGUEI. Jesús M. de. La encuesta de fecundidad de 1977 del Inst. Nacional de Estadistica, 14:141.

OLTRA, Benjamín. Sobre los datos lingüisticos en Catalunya, 14:135.

OlTRA, Benjamín. Grupos de interés e intelectuales en Dahrendorf, 4:165.

RAMA, Carlos M. Elementos para una sociología de las migraciones: el caso de los europeos en América Latina, 2:126.

TLILA, Antonio. Las cooperativas agrarias en el Pirineo - Una posible respuesta a Las agriculturas de alta montaña, 1:152.

URQUIDI, Víctor L. Sesión inaugural de la Sexta Asamblea General del Consejo Latinoamericano de Ciencias Sociales, 1:146.

\section{DOCUMENTS}

D'ORS, Eugenio. Los pequeños contemporáneos: Una encuesta sobre el ideal vital y profesional de los niños en Catalunya, 1921, 14:153.

SZCZEPANSKI, Jan. El método biográfico, 10:231.

WEBER, Max. La sociologia de Simmel, 15:145.

\section{Debats}

ALCALDE, Carmen

La mujer en la guerra civil española, 9: 297.

Presentación.

AUBET, María José. El último error de Rosa Luxemburg.

FALCON, Lidia. La emancipación del proletariado no es prioritaria a la de la mujer.

SuBIRATS, Marina. La dona i la participació politica. 